\title{
Performance comparison of series and parallel damped LCL filters using 5-level voltage source converter
}

\author{
Ibrahim Haruna Shanono ${ }^{1,2} \cdot$ Nor Rul Hasma Abdullah ${ }^{1} \cdot$ Hamdan Daniyal $^{1} \cdot$ Aisha Muhammad $^{3}$
}

Received: 28 August 2019 / Accepted: 6 February 2020 / Published online: 22 February 2020

(c) Springer Nature Switzerland AG 2020

\begin{abstract}
The high harmonic content produced by conventional converters has resulted in the increased system size and cost, due to the need for large-sized low-order harmonic passive filters and cooling system requirement. Given that, multilevel inverters and special modulation techniques were developed to suppress or eliminate the low-frequency harmonics and the left behind high-order ones are eliminated using a high-frequency small-sized filter. Hence, this paper designs and compares the total harmonic distortion (THD) and efficiency values of three set of filters, namely LCL filter, LCL with series and parallel resistance on a novel five-level multilevel voltage source inverter topology. The novelty lies with the proposed inverter, which, apart from using a single direct current source, it can extend it elimination capability beyond the normal five level using the concept of multiple switching per step and an optimised selective harmonic elimination pulse width modulation. The converter can eliminate eleven lower-order odd nontriplen harmonics, hence making the 37 th harmonic at $1.85 \mathrm{kHz}$ to be the first dominant harmonic. At 2-kW loading, two of the filters have THD below 5\%, therefore satisfying the IEEE 519 standard. The parallel resistance damped filter (LCL-P-R) has less THD value but poor efficiency due to the resistance introduced into the circuit. The study was carried out using PSIM and MATLAB software.
\end{abstract}

Keywords Multilevel inverters · Total harmonic distortion · LCL filters · Voltage source inverters (VSI)

\begin{tabular}{llll}
\multicolumn{2}{l}{ Abbreviations } & IGBT & \multicolumn{2}{l}{ Insulated gate bipolar junction transistors } \\
THD & Total harmonic distortion & FFT & Fast Fourier transform \\
MLI & Multilevel inverters & \multicolumn{2}{c}{ List of symbols } \\
LCL & Inductor capacitor inductor & fsw & Switching frequency \\
SHE-PWM & Selective harmonic elimination pulse width & $M$ & Modulation index \\
& modulation & $N$ & Angles per-quarter waveform \\
LCL-P-R & LCL parallel resistance damped filter & $n$ & Nth harmonics \\
LCL-S-R & LCL series resistance damped filter & $h_{n}$ & Amplitude of coefficient \\
VSI & Voltage source inverters & Pg & Active power \\
DC & Direct current & Qc & Reactive power \\
MVSI & Multilevel voltage source inverters & $G_{(s)}$ & Transfer function \\
DiC & Diode clamp & & \\
FC & Flying capacitor & & \\
NPC & Neutral point capacitor & & \\
CHB & Cascaded H-bridge & & \\
SMPS & Switch mode power supplies & &
\end{tabular}

$\triangle$ Ibrahim Haruna Shanono, snnibrahim01@gmail.com | ${ }^{1}$ Faculty of Electrical and Electronics Engineering, Universiti Malaysia Pahang, 26600 Pekan, Pahang, Malaysia. ${ }^{2}$ Department of Electrical, Faculty of the Engineering, Bayero University, Kano, Nigeria. ${ }^{3}$ Department of Mechatronics, Faculty of the Engineering, Bayero University, Kano, Nigeria. 


\section{Introduction}

Energy conversion has been the centre of discussion in recent times due to the significant advancements achieved in renewable energy technology $[1,2]$. An effective energy conversion requires the service of multilevel voltage source inverters (MVSI), which serves as the interface between the renewable source (solar, wind, etc.) and the load [3]. MVSI appears to have overcomes the numerous drawbacks posed by the conventional two-level topologies $[4,5]$. Its modular nature makes it possible to achieve a high power rating by concatenating smaller power modules $[4,6]$. In the event of damage/ fault, it modularity warrants the ease of having component replacement and repair. Unlike the conventional topology, MVSI provides better switching freedom with minimum switching loses for the same voltage level [7]. The elimination of lower-order harmonic shrinks the size of the filter passive components since the remaining harmonics is at a high frequency [8].

Several new and hybrid MVSI topologies were proposed, most of which are modified and upgraded version of the conventional diode clamp ( $\mathrm{DiC})$, flying capacitor (FC), neutral point capacitor (NPC) and cascaded $\mathrm{H}$-bridge (CHB) $[7,9,10]$. The converter topology and control strategy determine the type of filter needed as an interface to the grid [11].

Figure 1 shows the stages involved in the renewable energy system. It depicts the energy harvesting/harnessing, conversion and the distribution stages [12], and similar set-up applies to standalone configurations. Each sub-block stage is a broad area with enormous potential research output. The primary function of the filtering device is to mitigate the unwanted signals in the inverter output to satisfy the IEEE standard grid requirements [13]. The nonlinearity of power converters results in the harmonic generation at its output, which, if not addressed, will inject the unwanted output components into the entire system. The harmonics are said to be integer multiples of the fundamental frequency ( $2 \mathrm{nd}, 3 \mathrm{rd}, 4 \mathrm{th}$....etc.).
Harmonics results in pulsating torque in motors and system overheat, which leads to insulation damage, efficiency degradation and possible system shutdown [14].

Based on the half-wave symmetry theorem the even harmonics present in any periodic signal cancels out. Therefore, $2 \mathrm{nd}, 4 \mathrm{th}, 6 \mathrm{th}, 8^{\text {th }}$, etc., harmonics disappear in the phase output $[15,16]$.

Filters are categorised into active and passive based on the nature/type of the components. The predominant type is the passive filter; this is due to its simplicity, abundance and cheap components $[17,18]$. There are quite a few filter design procedures, including ripple calculation, iterative algorithms and power loss optimisation [19-21].

Power electronic converters have a wide range of applications ranging from switch mode power supplies (SMPS), electric drives, renewable energy conversion, etc. [22-25]. The primary issue associated with them is the harmonics found at their output, which has a direct relationship with the modulation strategy involved. The harmonics appear at the switching frequency (fsw) and its multiples [26].

Converters with less harmonic-order elimination capability tend to have larger-sized filter components, hence increasing its physical size, weight and cost [21]. This issue is addressed by employing special modulation technique or new converter topology or both to eliminate the lower harmonics, hence, leaving behind only the higher-order ones that require a smaller-sized filter component $[4,16$, 21].

In an effort to improve the filter power density and attenuation capability, several LCL filter topologies were proposed [27-35].

LCL passive filter is a third-order filter that has numerous advantages over the $L$ and $L C$ filters. It has remarkable attenuation ability at high frequency. However, its major downside is the resonance effect. The resonance effect leads to either voltage or current instability as the inverter frequency of operation approaches the system resonance frequency [35]. One suitable solution to reduce or eliminate the resonance effect is to introduce an additional resistor to the filter circuit, which serves as a damper $[36,37]$. There are two ways of connecting the damping

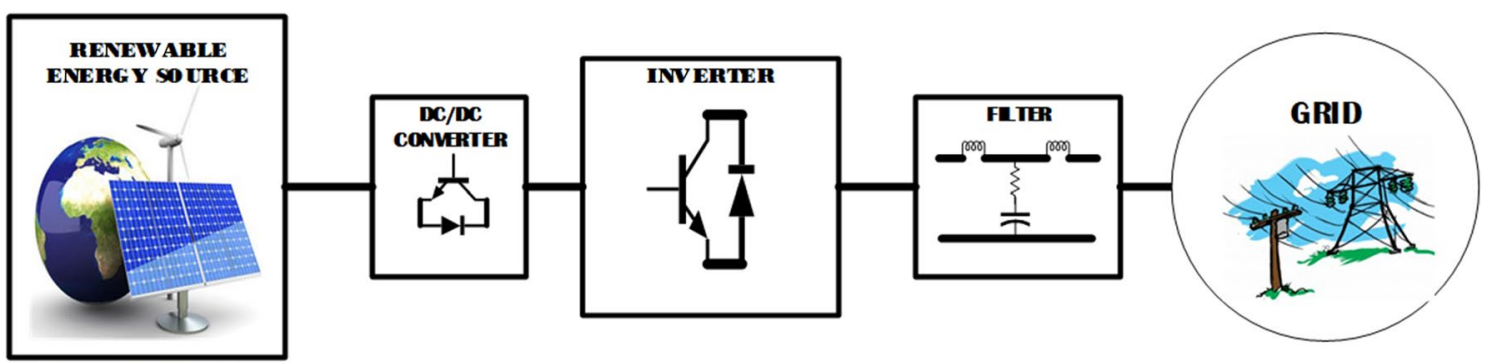

Fig. 1 System block 
resistance, i.e. the $L C L$ filter with series resistors (LCL-S$\mathrm{R})$ and also the parallel resistor (LCL-P-R) connections. In some researches, it has been shown that the introduction of parallel damping resistors is better at suppressing the resonance effect and the THD component as compared to the series-configured one $[4,9,13]$. However, the majority of researchers fail to report the efficiency deterioration caused by incorporating the passive component into the system [38-40].

The contribution of this article is that it is the first to apply and assess the harmonic content of the proposed 5-level voltage source inverter presented in Shanono et al. [4] using LCL, LCL-R-S and LCL-R-P passive filters. In addition, most research articles only analyse and report harmonic elimination capabilities of a specific filter at a fix output power, ignoring that the inverter output THD content along with the filter eliminating ability changes with an increase in loading. Therefore, this article addresses the issue by comparing the output THD variation of the three sets of filters with different output powers. Moreover, few research articles analyse the effect of the filtering circuit on the efficiency of the inverter and the efficiency variation with increasing output power. Hence, this article analyses and compares the efficiency of all the three filters against a varying output load.

\section{Multilevel converter topologies}

This section describes the proposed inverter topology mode of operation, how the switching angles were obtained, and the switching function used to realise the five-level voltage waveform.

\subsection{Inverter circuit description}

Figure 2 is the inverter circuit configuration used to generate the 5-level voltage waveform. It comprises of two cascaded $\mathrm{H}$-bridge topology modules powered through the same input source. Each module output terminal is connected to a special transformer having two independent primary and series-connected secondary windings with 1:1 and 1:1 turn ratio, respectively. The single DC input source could either be a photovoltaic, lithium-ion batteries or fuel cells. Insulated gate bipolar junction transistors (IGBT) $\left(S_{11 \mathrm{a}}\right.$ to $\left.S_{24 \mathrm{~b}}\right)$ were the power electronic switches, with each of the gating terminal controlled using an offline precalculated switching angle stored in a pulse generator. With an appropriate control signal, each of the $\mathrm{H}$-module is capable of generating three voltage steps $(-\mathrm{VDC}, 0$ and

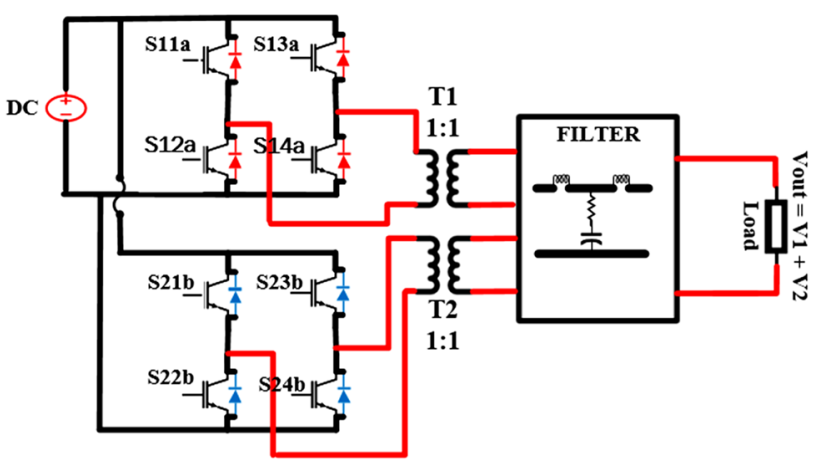

Fig. 2 Converter circuit topology

VDC). Table 1 gives the state of each switch and the corresponding terminal voltages.

Figure 3 shows a sketch of the 5 -level voltage waveform to be generated by the converter topology. The first module generates terminal voltage $V_{01}$ using switches $S_{11 a}$ to $S_{14 a}$. The voltage is used for step synthesis by adding a series of notches to the output voltage $\left(V_{\text {out }}\right)$, while the second module generates $V_{02}$ with switches $S_{21 \mathrm{~b}}$ to $S_{24 \mathrm{~b}}$ and is for the bulk power transfers. Note that this research is not intended to address switching and power balancing in both electronic switches and transformers, and it is interested in voltage step level generation and the filters harmonic elimination.

\subsection{Switching angles}

The multilevel inverter is controlled using selective harmonic elimination (SHE) pulse width modulation (PWM) technique. Therefore, the switching angles are obtained by optimally solving the generated nonlinear transcendental equations using a genetic algorithms optimisation technique. Equation (1) shows the generalised output waveform equation. There are twelve angles with each representing a single notch $(N)$ added per-quarter waveform at predetermined points. Equation (1) with $n=1$ represents the fundamental component and is equated to a specific value based on the modulation index $(M)$, whereas all other equations with $(n>1)$ representing the harmonic amplitudes are equated to zero. Based on selective harmonic elimination theory, the converter eliminates $(N-1)$ harmonics, meaning all the 11 lower-order odd harmonics. In the prior study presented in [4], only the odd nontriplen harmonics were selected for elimination, i.e. (5th, 7 th, 11 th, 13th, 17th, 19th, 23rd, 25th, 29th, 31st, 35th). 
Table 1 Switching combinations

Fig. 3 Five-level waveform with $3 / 9$ distribution ratio

\begin{tabular}{lllllllll}
\hline Voltage & \multicolumn{7}{l}{ Switching states } & \multicolumn{1}{l}{} \\
\cline { 2 - 8 } & $S_{11 \mathrm{a}}$ & $S_{12 \mathrm{a}}$ & $S_{13 \mathrm{a}}$ & $S_{14 \mathrm{a}}$ & $S_{21 \mathrm{~b}}$ & $S_{22 \mathrm{~b}}$ & $S_{23 \mathrm{~b}}$ & $S_{24 \mathrm{~b}}$ \\
\hline 0 & 1 & 0 & 1 & 0 & 1 & 0 & 1 & 0 \\
$+\mathrm{E}$ & 1 & 0 & 0 & 1 & 1 & 0 & 1 & 0 \\
$+\mathrm{E}$ & 1 & 0 & 1 & 0 & 1 & 0 & 0 & 1 \\
0 & 0 & 1 & 0 & 1 & 0 & 1 & 0 & 1 \\
$-\mathrm{E}$ & 0 & 1 & 1 & 0 & 1 & 0 & 1 & 0 \\
$-\mathrm{E}$ & 1 & 0 & 1 & 0 & 0 & 1 & 1 & 0 \\
$+2 \mathrm{E}$ & 1 & 0 & 0 & 1 & 1 & 0 & 0 & 1 \\
$-2 \mathrm{E}$ & 0 & 1 & 1 & 0 & 0 & 1 & 1 & 0 \\
\hline
\end{tabular}

$h_{1}=\frac{4 * E}{\pi}\left\{\begin{array}{c}\cos \alpha_{1}-\cos \alpha_{2}+\cos \alpha_{3}+\cos \alpha_{4}-\cos \alpha_{5}+\cos \alpha_{6}-\cos \alpha_{7}+\cos \alpha_{8} \\ -\cos \alpha_{9}+\cos \alpha_{10}-\cos \alpha_{11}+\cos \alpha_{12}\end{array}\right\}$

$h_{n}=\frac{4 * E}{n \pi}\left\{\begin{array}{c}\cos n \alpha_{1}-\cos n \alpha_{2}+\cos n \alpha_{3}+\cos n \alpha_{4}-\cos n \alpha_{5}+\cos n \alpha_{6} \\ -\cos n \alpha_{7}+\cos n \alpha_{8}-\cos n \alpha_{9}+\cos n \alpha_{10}-\cos n \alpha_{11}+\cos n \alpha_{12}\end{array}\right\}$

The amplitude of the fundamental component is controlled by the modulation index $(M)$ and is given by the expression.

Modulation Index $(M)=\frac{h_{1}}{E}$

For all $n=1$.

While $M=0$ for all $n+1$.

Hence, using Eqs. (1), (2) and (3) are used to generate the nonlinear transcendental equations that can be expressed as:
Table 2 Calculated switching angles

\begin{tabular}{lllll}
\hline$\left(s n / \alpha_{n}\right)$ & $0-90$ & $90-180$ & $180-270$ & $270-360$ \\
\hline 1 & 13.40246 & 103.40246 & 193.4025 & 283.4025 \\
2 & 15.67567 & 105.67567 & 195.6757 & 285.6757 \\
3 & 19.61681 & 109.61681 & 199.6168 & 289.6168 \\
4 & 35.50001 & 125.50001 & 215.5000 & 305.5000 \\
5 & 37.80673 & 127.80673 & 217.8067 & 307.8067 \\
6 & 46.26136 & 136.26136 & 226.2614 & 316.2614 \\
7 & 48.24797 & 138.24797 & 228.248 & 318.248 \\
8 & 54.85481 & 144.85481 & 234.8548 & 324.8548 \\
9 & 58.37752 & 148.37752 & 238.3775 & 328.3775 \\
10 & 61.01313 & 151.01313 & 241.0131 & 331.0131 \\
11 & 83.87128 & 173.87128 & 263.8713 & 353.8713 \\
12 & 86.01930 & 176.0193 & 266.0193 & 356.0193 \\
\hline
\end{tabular}




$$
\begin{aligned}
& {\left[\begin{array}{c}
\cos \alpha_{1}-\cos \alpha_{2}+\cos \alpha_{3}+\cos \alpha_{4}-\cos \alpha_{5}+\cos \alpha_{6}-\cos \alpha_{7}+\cos \alpha_{8} \\
-\cos \alpha_{9}+\cos \alpha_{10}-\cos \alpha_{11}+\cos \alpha_{12}
\end{array}\right]=\frac{M \pi}{4}} \\
& {\left[\begin{array}{l}
\cos 5 \alpha_{1}-\cos 5 \alpha_{2}+\cos 5 \alpha_{3}+\cos 5 \alpha_{4}-\cos 5 \alpha_{5}+\cos 5 \alpha_{6}-\cos 5 \alpha_{7}+\cos 5 \alpha_{8} \\
-\cos 5 \alpha_{9}+\cos 5 \alpha_{10}-\cos 5 \alpha_{11}+\cos 5 \alpha_{12}
\end{array}\right]=0}
\end{aligned}
$$

$$
\left[\begin{array}{c}
\cos 35 \alpha_{1}-\cos 35 \alpha_{2}+\cos 35 \alpha_{3}+\cos 35 \alpha_{4}-\cos 35 \alpha_{5}+\cos 35 \alpha_{6}-\cos 35 \alpha_{7} \\
+\cos 35 \alpha_{8}-\cos 35 \alpha_{9}+\cos 35 \alpha_{10}-\cos 35 \alpha_{11}+\cos 35 \alpha_{12}
\end{array}\right]=0
$$

Equations (4)-(14) are the nonlinear transcendental equations that are solved using the optimisers to obtain the optimum switching angles (Table 2).

\section{Filter design}

This section discusses the three types of filters used in this research, their circuits configuration, transfer function and the design steps.

\subsection{LCL filter}

Due to the large inductor size, time delay and resonance issues associated with the LC filter, the LCL filter was introduced to address the said problems [13]. It is a third-order filter because it has three energy storage components with an attenuation factor of $60 \mathrm{db}$ per decades. Its circuit is distinct from the LC filter in that it has an additional series-connected inductance between the capacitor and the grid. This filter effectively addresses the problem of size and time delay, but still has resonance issues, which, if not addressed, can cause instability in the voltage and current at the resonance frequency. Figure 4 shows the LCL filter circuit arrangement.

Some rules and approximations need to be followed when designing an LCL filter. One of which is that the inductor voltage drop should not exceed $5-10 \%$ of the network root-mean-square of the rated voltage [14],

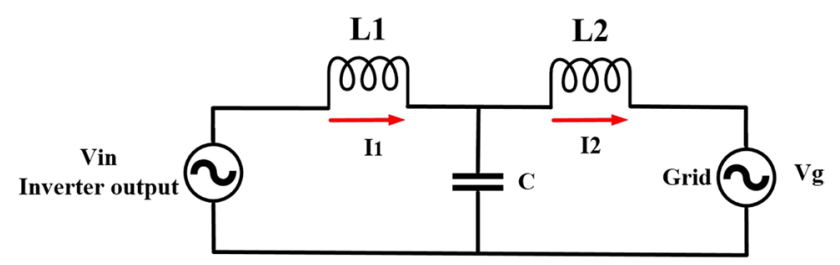

Fig. 4 LCL filter whereas the current ripples should not be more than $25 \%$ of the rated current. In most cases, it lies within the range of $15-25 \%[1,4]$. Lastly, the reactive power absorbed by the capacitor (Qc) should be less than the generated active power (Pg). With the help of the above assumptions, the below expressions are derived.

$I_{L \max } * X_{L}=I_{L \max } *(2 \pi L f)<0.05 * V_{\text {in }}$

$\mathrm{Qc}=\frac{\mathrm{Vg}^{2}}{\mathrm{Xc}}=V_{\text {in }} *(2 \pi C f)=0.01 * \mathrm{Pg}$

$L_{1}=4 L_{2}$

Wres $=\sqrt{\frac{\left(L_{1}+L_{2}\right)}{L_{1} * L_{2} * C}}$

$R=\frac{1}{3 \text { WresC }}$

The passive components of all the three set of filters are calculated using Eqs. (15)-(19), as shown below:

The parameters obtained are presented in Table 3 below.

The below expression gives the above circuit transfer function. It is used to analyse the filter stability margin using a bode plot.

$G_{(s)}=\frac{I_{2}}{V_{\text {in }}}=\frac{1}{\left(L_{1}+L_{2}\right) S+L_{1} L_{2} C S^{3}}=\frac{1}{3.047 e-11 S^{3}+0.0008933 S}$

Table 3 List of filter components

\begin{tabular}{lllll}
\hline Filter type & $L_{1}(\mathrm{mH})$ & $L_{2}(\mathrm{mH})$ & $C(\mu \mathrm{F})$ & $R(\Omega)$ \\
\hline $\mathrm{LCL}$ & 0.715 & 0.179 & 239 & \\
LCL series damped & 0.715 & 0.179 & 239 & 0.39 \\
LCL parallel damped & 0.715 & 0.179 & 239 & 3.90 \\
\hline
\end{tabular}


Fig. 5 a Series damped filter. $\mathbf{b}$ Parallel damped filter

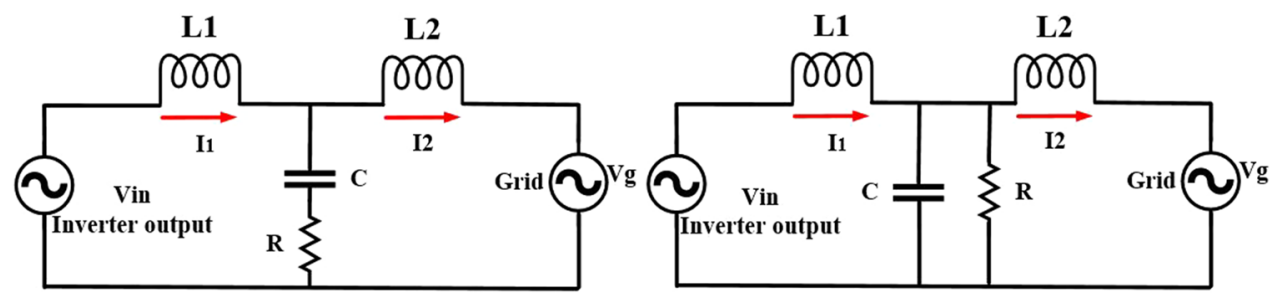

(a)

(b)
The resonance issue is addressed by damping the system. The damping is achieved by connecting a resistor either in series or in parallel to the filter capacitor. Figure $5 \mathrm{a}, \mathrm{b}$ represents the two filter circuit arrangements, respectively. The circuits transfer function for both the two circuits is given in Eqs. (21) and (22). The resistance value needs to be carefully selected to minimise losses due to $l^{2} R$.
The transfer function for the series damping configuration.

$$
\begin{aligned}
G_{(s)} & =\frac{I_{2}}{V_{\text {in }}}=\frac{1+R C S}{\left(L_{1}+L_{2}\right) S+\left(L_{1}+L_{2}\right) R C S^{2}+L_{1} L_{2} C S^{3}} \\
& =\frac{9.309 \mathrm{e}-05 S+1}{3.047 \mathrm{e}-11 S^{3}+8.316 \mathrm{e}-08 S^{2}+0.0008933 S}
\end{aligned}
$$
by:
Fig. 6 a Unfiltered inverter output voltage and current waveform. b Unfiltered voltage and current FFT

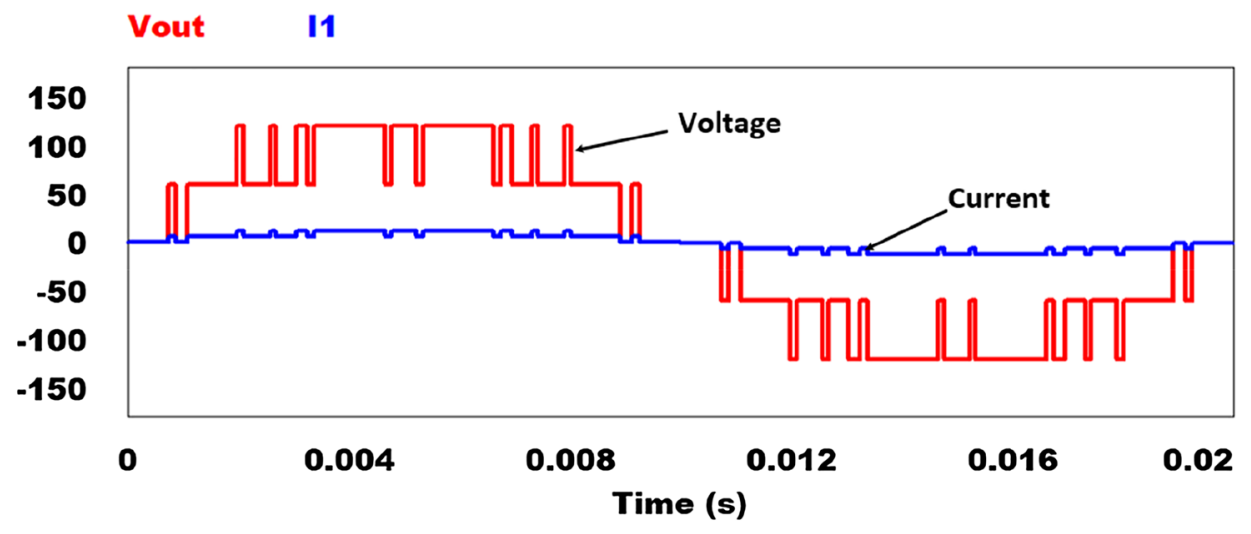

(a)
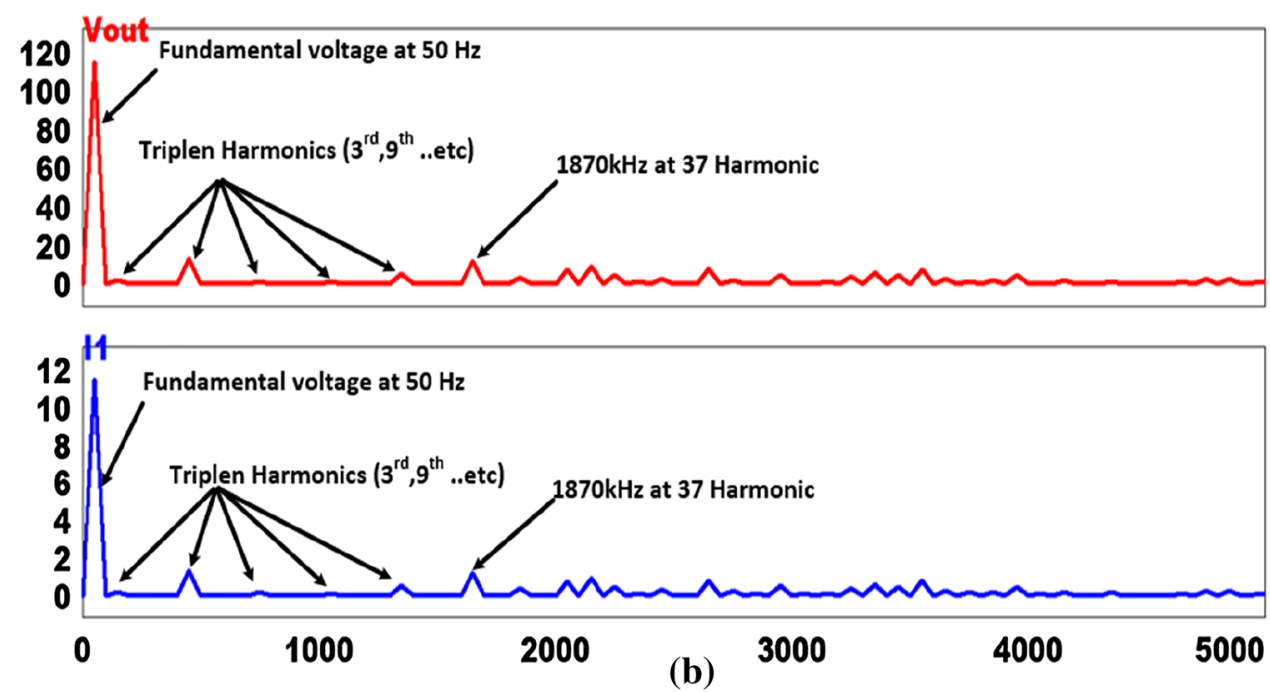


$$
\begin{aligned}
G_{(S)} & =\frac{I_{2}}{V_{\text {in }}}=\frac{R}{\left(L_{1}+L_{2}\right) R S+\left(L_{1} L_{2}\right) S^{2}+L_{1} L_{2} R C S^{3}} \\
& =\frac{3.9}{1.188 \mathrm{e}-10 S^{3}+1.276 \mathrm{e}-07 S^{2}+0.003484 S}
\end{aligned}
$$

\section{Simulation results and discussion}

This section presents the inverter output current and voltage waveforms along with their FFT. Based on the inverter output requirements, three sets of filters were designed and analysed. The stability margin for all the filters is ascertained using bode plot. The filters THD and efficiency variation with respect to output power are presented.

\subsection{Inverter output without a filter}

The proposed inverter topology is simulated in PSIM software controlled using the obtained switching angles to generate the five-level output voltage. Figure 6 a shows the current and voltage waveforms across a resistive load. The benefit of SHE-PWM technique is it reduces the inverter output harmonic contents by eliminating lower-order harmonics. Figure $6 \mathrm{~b}$ shows the fast Fourier transform (FFT) for the output voltage and current. As seen, all the selected lower harmonics are eliminated in both voltage and current waveforms. The only visible harmonics at lower frequency are the triplens which are expected to be eliminated in a 3-phase system. The odd nontriplen dominant harmonic becomes visible at the 37th order, which is not within the SHE-PWM elimination range. Hence, this results in the needs for a smaller size filter with cutoff frequency at $1850 \mathrm{~Hz}$. The un-filtered inverter total harmonic distortion (THD) is $27.46 \%$ at $2 \mathrm{~kW}$, which is quite higher than the acceptable $5 \%$.

\subsection{Inverter output with LCL filter}

To address the time delay, large inductor size and resonance issues associated with passive filters, an LCL filter was introduced. Figure 7a shows the $\mathrm{LCL}$ filter output current and voltage waveforms at light load. LCL is capable of addressing the inductor size problem and as well reduces the total harmonic distortion (THD) down to $5.15 \%$ at $2 \mathrm{~kW}$. Though it did not satisfy the $5 \%$ standard requirement, all the higher-order harmonics have been suppressed. Figure $7 \mathrm{~b}, \mathrm{c}$ represents the output FFT and the filter bode plot, respectively. As seen in the frequency response, there is a peak amplitude overshoot occurring at a resonance frequency which needs to be addressed. The circuit needs a damper, to suppress the overshoot. This brought about the concept of the LCL series and parallel filter into the picture [15].

\subsection{LCL filter with series resistance (LCL-S-R)}

To solve the resonance problem associated with the LCL filter, a damping resistor is connected in series with the filter capacitor. Figure 8a shows the filtered output waveform at $2-\mathrm{kW}$ loading. It has fewer ripples as compared with the former indicating reduction in the inverter output THD, which stood at $4.47 \%$. Figure $8 \mathrm{~b}$ shows its FFT plot, with no lower and higher harmonics visible. It can be seen from Fig. $8 \mathrm{c}$ that the introduction of resistance into the circuit has addressed the overshoot problem at resonance. This results in a better stable frequency response and smooth phase transition at the resonance frequency. The drawback of this filter arrangement is a drop in efficiency due to $l^{2} R$ heat dissipation.

\subsection{LCL filter with parallel resistance (LCL-P-R)}

The filter-damping factor and output THD can as well be improved by connecting a resistor in parallel with the capacitor. This arrangement has the least THD value of $4.17 \%$ at $2 \mathrm{~kW}$. Figure $9 \mathrm{a}, \mathrm{b}$ shows a smooth inverter output waveforms and harmonic-free FFT plot at the same $2-k W$ loading. The filter frequency response in Fig. $9 \mathrm{c}$ is similar to the previous Fig. $8 \mathrm{c}$ with damped overshoot at the resonance frequency.

\subsection{Efficiency and THD variation with output power}

The literature suggests that the harmonic content of an inverter has an inverse relationship with its output power, as the output power increases, so the THD decreases. To ascertain this theorem with our converter topology and filters, the output harmonics of the topology with and without the filters are measured and plotted as shown in Fig. 10. The plot verifies the THD and output power relationship. The without filter curve obeys the theorem, but as seen, it has a minimal variation with increased loading, whereas the ones with filter experience significant variations as the output power increases. The LCL-P-R has the least THD value within the entire range and then followed by LCL-S-R and lastly LCL filter.

The efficiency of the inverter with various filters is assessed as the output power is varied. From Fig. 11, 
Fig. 7 a LCL filtered inverter output voltage and current waveform. b LCL filtered voltage and current FFT c LCL filter bode plot

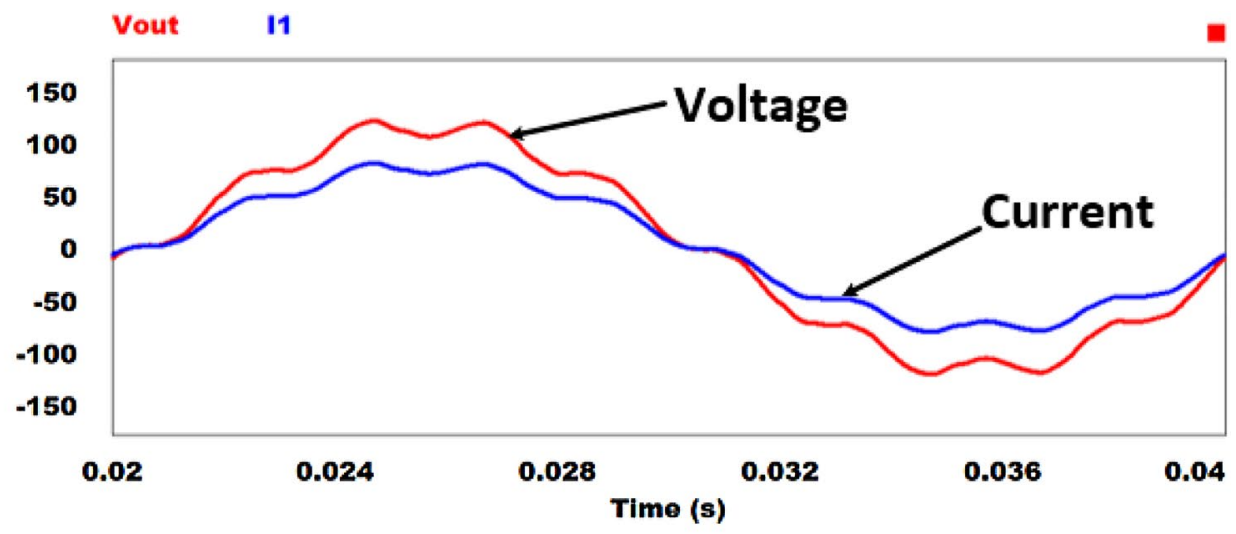

(a)
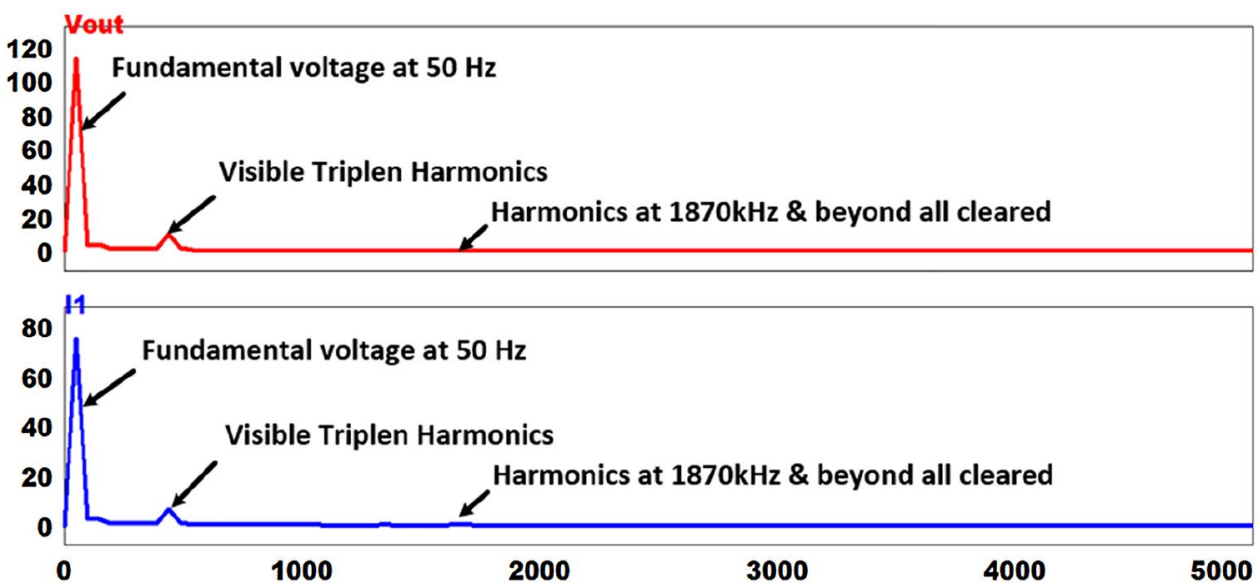

(b)

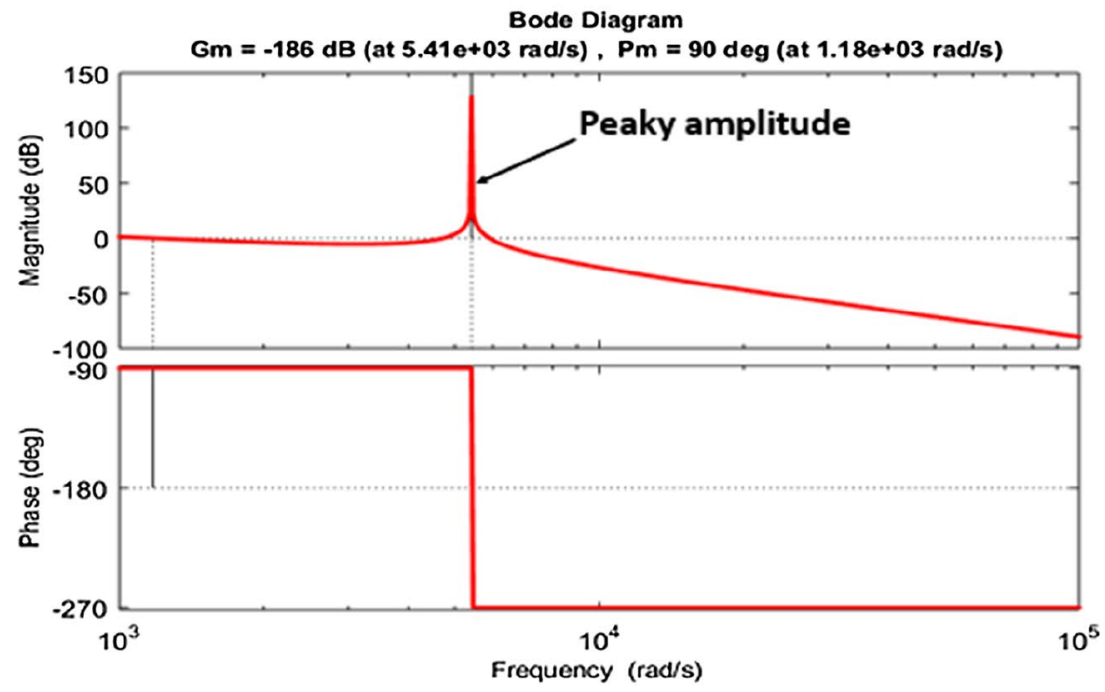

(c) it can be seen that all the curves obey the efficiency vs output power exponential relationship. As expected, the damped filters have the least efficiency values due to the heat-dissipating component (resistor) introduced. The LCL$\mathrm{S}-\mathrm{R}$ has a better efficiency between 1 and the $2 \mathrm{~kW}$ range, and the efficiency begins to deteriorate as the inverter is 
Fig. 8 a LCL series resistance filtered inverter output voltage and current waveform. $\mathbf{b}$ $\mathrm{LCL}$ series resistance filtered voltage and current FFT. c LCL series resistance filter bode plot

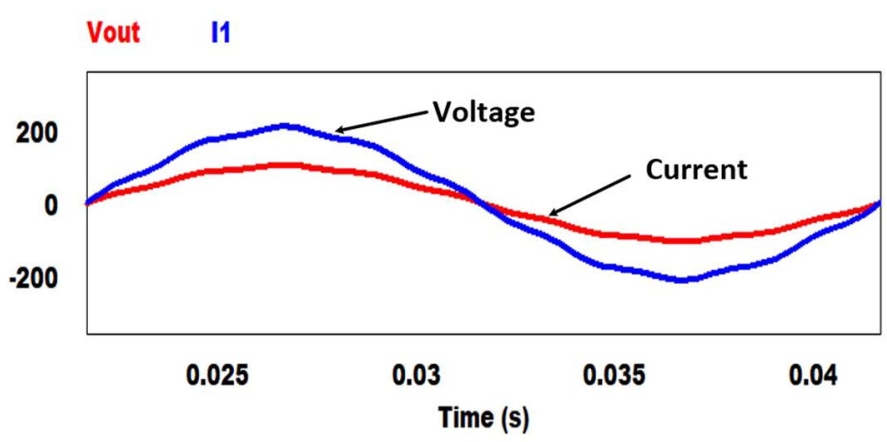

(a)
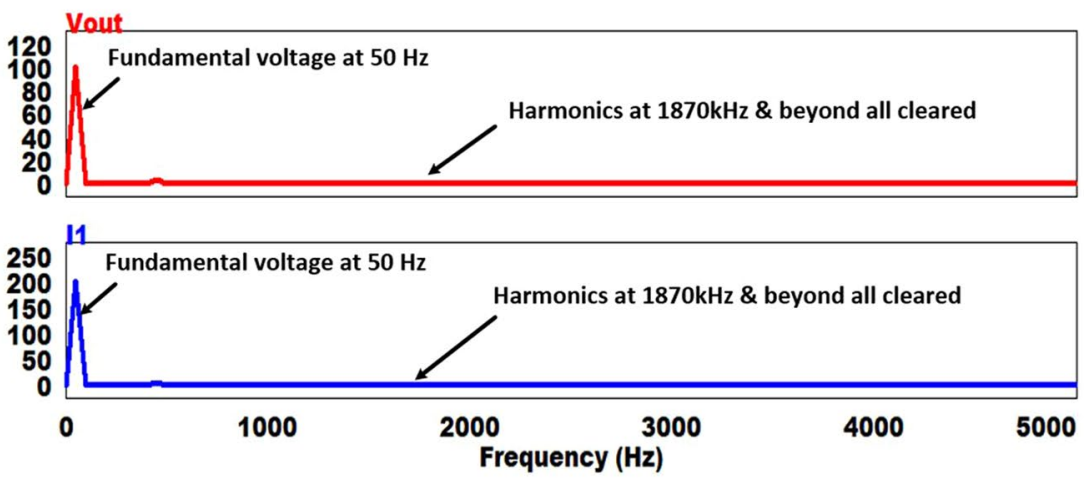

(b)

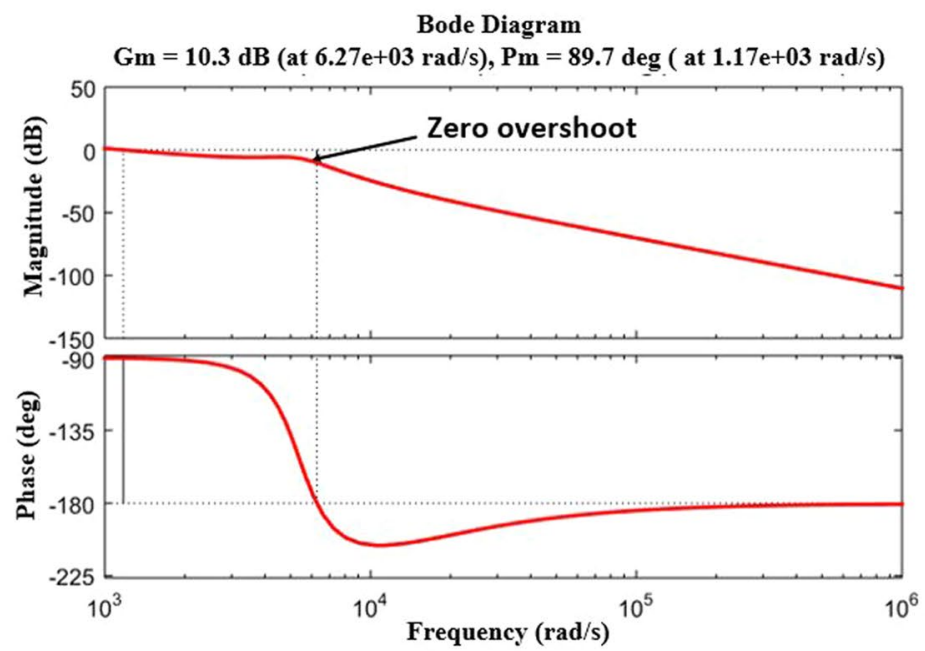

(c) overloaded. The same deterioration is observed in the $\mathrm{LCL}$ as well.

\section{Conclusion}

The paper analyses the THD and efficiency values of a 5-level cascaded $\mathrm{H}$-bridge inverter that is controlled using selective harmonic elimination method (SHE-PWM). The proposed inverter successfully eliminates the 11 lowerorder harmonics. Even with the elimination, the THD is still higher than the IEEE. 519 requirements. To satisfy the requirement, a filter is needed to mitigate the remaining higher-order harmonics. The filters harmonic elimination capability was evaluated by measuring the THD values obtained in both the voltage and current output waveforms across a resistive load. Figure 12 presents the THD comparison chart of the inverter output with and without 
Fig. 9 a LCL parallel resistance filtered inverter output voltage and current waveform. b LCL parallel resistance filtered voltage and current FFT. c LCL parallel resistance filter bode plot

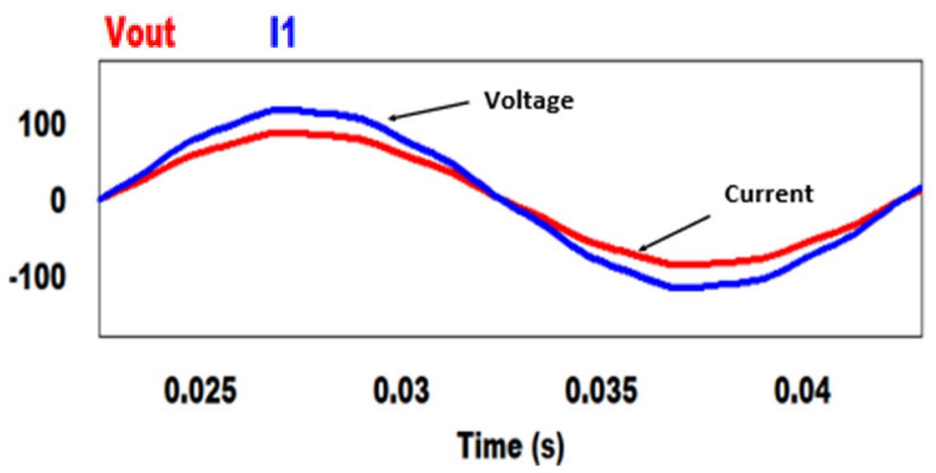

(a)
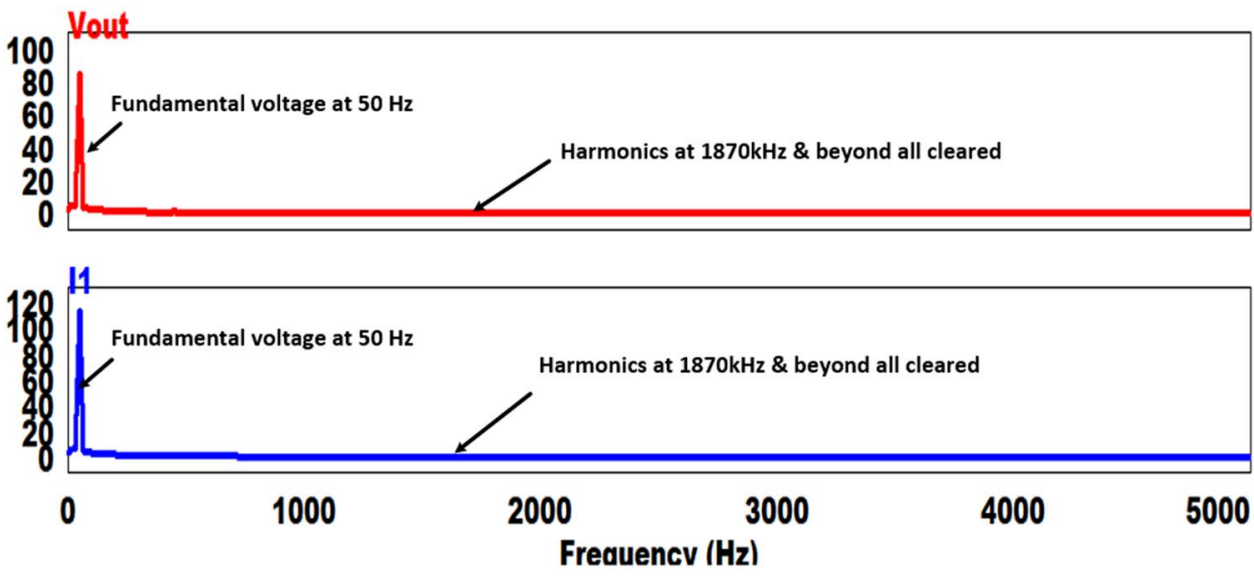

(b)

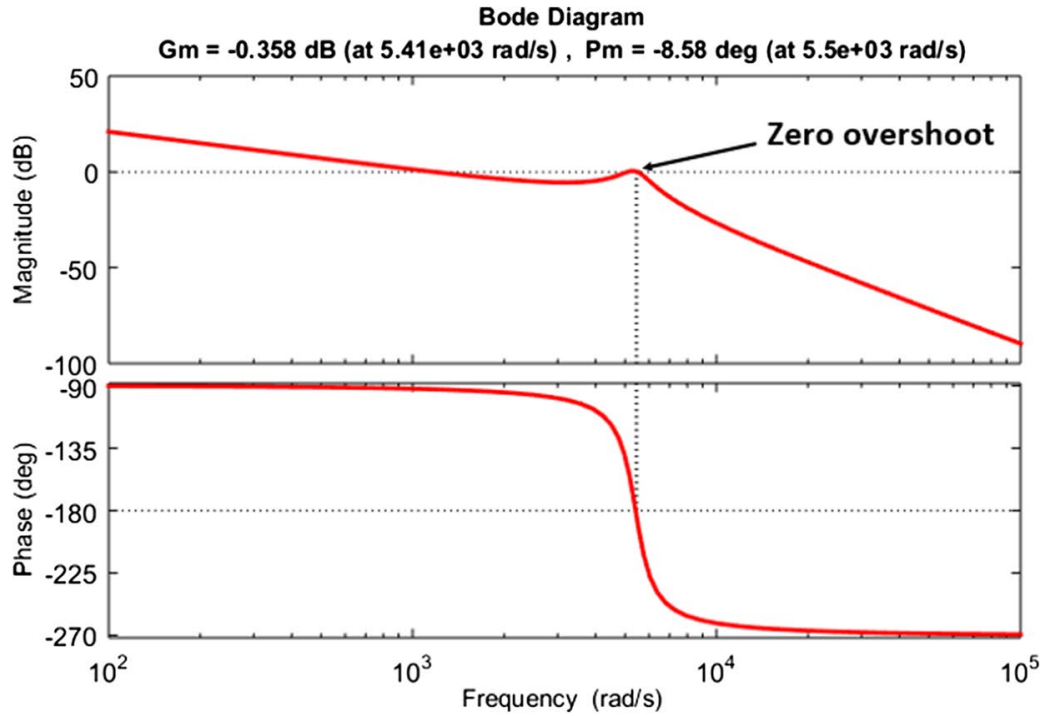

(c) the filters. As seen both the damped LCL filters satisfy the IEEE requirement at $2 \mathrm{~kW}$ except for the un-damped $\mathrm{LCL}$ filter.
With respect to efficiency value at $2 \mathrm{~kW}$, it can be deduced from Fig. 13 that LCL has the highest efficiency value followed by LCL-S-R, then without a filter and then the least LCL-P-R with approximately $64.75 \%$. The reduced 


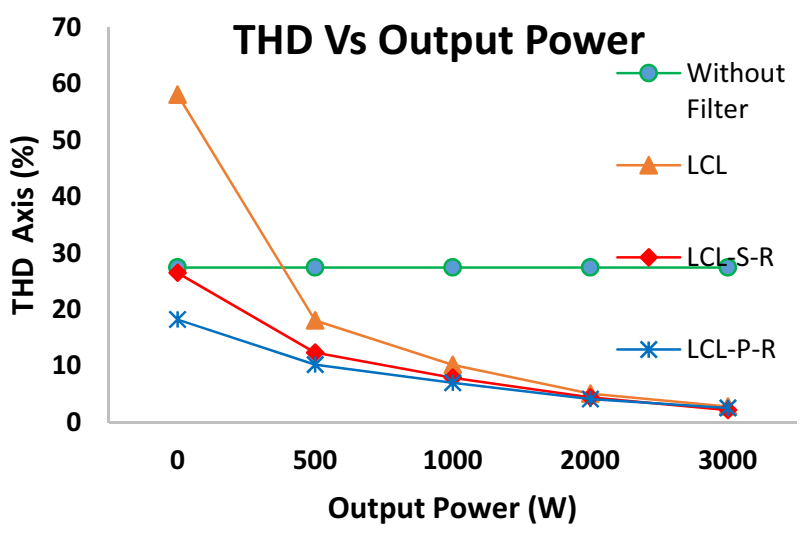

Fig. 10 THD versus output power relationship

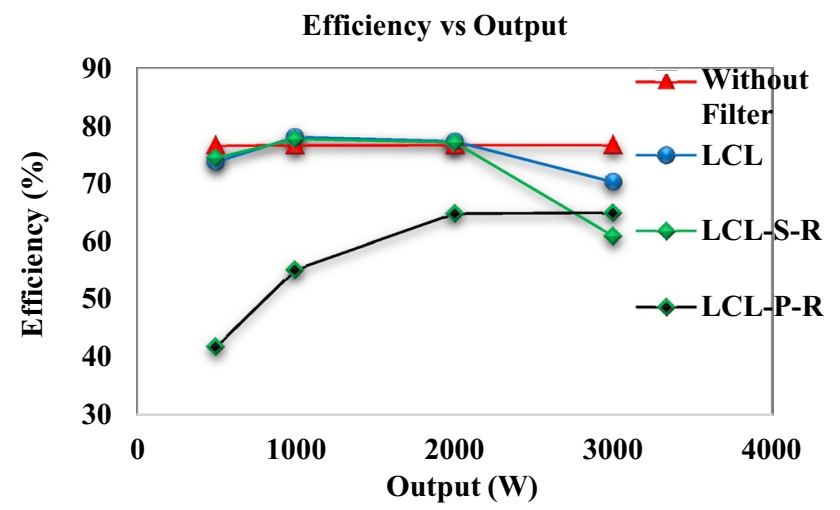

Fig. 11 Efficiency versus output power relationship

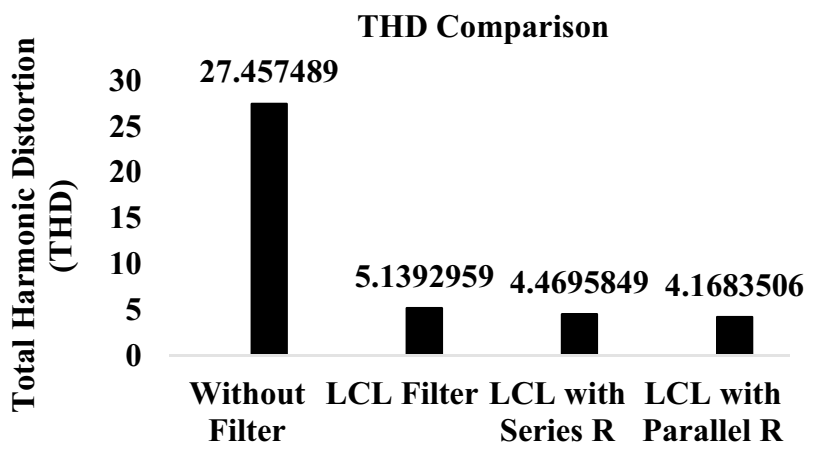

Fig. 12 THD comparison histogram at $2 \mathrm{kw}$

efficiency value in the later has to do with the resistance added in the circuit, which happens to be a lossy component. Therefore, a careful choice of resistance should be made to minimise efficiency deterioration. Lastly, the inverter control strategy and the filters employed had succeeded in minimising the output THD. Hence, making the
Efficiency comparison at $2 \mathrm{KW}$ output

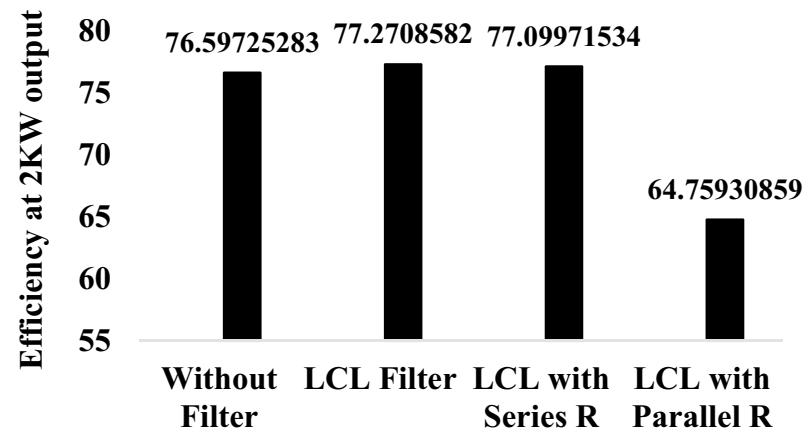

Fig. 13 Efficiency histogram comparison at $2 \mathrm{kw}$

inverter topology suitable in automotive and renewable energy applications. For future recommendations, the converter topology THD and efficiency characteristics can be investigated using different types of filter and modulation techniques.

Acknowledgements The authors gratefully acknowledge the financial support from Universiti Malaysia Pahang Grant, RDU1703226.

\section{Compliance with ethical standards}

Conflict of interest The authors declare that they have no conflict of interest.

\section{References}

1. He ZX, Xu SC, Li QB, Zhao B (2018) Factors that influence renewable energy technological innovation in china: a dynamic panel approach. Sustainability 10(124):1-30

2. Lin B, Zhu J (2019) Determinants of renewable energy technological innovation in China under $\mathrm{CO}_{2}$ emissions constraint. J Environ Manag 247(2019):662-671

3. Kumar YVP, Ravikumar B (2016) A simple modular multilevel inverter topology for the power quality improvement in renewable energy based green building microgrids. Electr Power Syst Res 140(2016):147-161

4. Shanono IH, Abdullah $\mathrm{NRH}$, Muhammad A (2018) Five-level single source voltage converter controlled using selective harmonic elimination. Indones J Electr Eng Comput Sci 12(3):888-896

5. Sinha A, Jana KC, Dasm MK (2018) An inclusive review on different multi-level inverter topologies, their modulation and control strategies for a grid-connected photo-voltaic system. Sol Energy 170(2018):633-657

6. Abd Halim W, Ganeson S, Azri M, Tengku Azam TNA (2016) Review of multi-level inverter topologies and its applications. J Telecommun Electron Comput Eng 8(2016):51-56

7. Venkataramanaiah J, Suresh Y, Panda AK (2017) A review on symmetric, asymmetric, hybrid and single dc sources based 
multilevel inverter topologies. Renew Sustain Energy Rev 76(1):788-812

8. Prabaharan N, Campana PE, Jerin RA, Palanisamy K (2019) A new approach for grid integration of solar photovoltaic system with maximum power point tracking using multi-output converter. Energy Procedia 159(2019):521-526

9. Shanono IH, Abdullah NRH, Muhammad A (2018) A survey of multilevel voltage source inverter topologies, controls, and applications. Int J Power Electron Drive Syst 9(3):1186-1201

10. Yuan X (2017) Derivation of voltage source multilevel converter topologies. IEEE Trans Ind Electron 64(2):966-976

11. Rockhill AA, Liserre M, Teodorescu R, Rodriguez P (2010) Grid-filter design for a multimegawatt medium-voltage voltage-source inverter. IEEE Trans Ind Electron 58(4):1205-1217

12. Liana J, Zhanga Y, Maa C, Yanga Y, Chaima E (2019) A review on recent sizing methodologies of hybrid renewable energy systems. Energy Convers Manag 199(2019):112027

13. Beres RN, Wang X, Liserre M, Blaabjerg F, Bak LC (2017) A review of passive power filters for three-phase. IEEE J Emerg Sel Top Power Electron 4(1):54-68

14. Vinayagam $A$ et al (2019) Harmonics assessment and mitigation in a photovoltaic integrated network. Sustain Energy Grids Netw 20(2019):100264

15. Shanono IH, Abdullah NRH, Daniyal H et al (2019) Selective harmonic elimination (SHE) based 3-phase multilevel voltage source inverter (VSI) for standalone applications. SN Appl Sci 1:1670. https://doi.org/10.1007/s42452-019-1726-3

16. Shanono IH, Abdullah NRH, Muhammad A (2018) 9-level voltage source inverter controlled using selective harmonic elimination. Int J Power Electron Drive Syst 9(3):1251-1262

17. Cheepati KR, Prasad TN (2016) Importance of passive harmonic filters over active harmonic filters in power quality improvement under constant loading conditions. IOSR J Electr Electron Eng 2(14):21-27

18. Kumar D, Zare F (2014) Analysis of harmonic mitigations using hybrid passive filters. In: 16th international power electronics and motion control conference and exposition. IEEE, Antalya, Turkey

19. Liserre $M$, Blaajberg $F$, Hansen $S$ (2005) Design and control of an LCL-filter-based three-phase active rectifier. IEEE Trans Ind Appl 41(5):1281-1291

20. Reznik A, Simoes M, Al-Durra A, Muyeen S (2014) LCL filter design and performance analysis for grid-interconnected systems. IEEE Trans Ind Appl 50(2):1225-1232

21. Shanono IH, Abdullah NRH, Muhammad A (2019) Filter design for a nine level voltage source inverter for renewable energy applications: methods and protocols. In: Zain Md et al (eds) 10th national technical seminar on underwater system technology. LNEE. Springer, Singapore, pp 571-585

22. Blaabjerg F, Teodorescu R, Liserre M, Timbus AV (2006) Overview of control and grid synchronisation for distributed power generation systems. IEEE Trans Ind Electron 53(5):1398-1409

23. Tang Y, Blaabjerg F, Loh PC, Jin C, Wang P (2015) Decoupling of fluctuating power in single-phase systems through asymmetrical half-bridge circuit. IEEE Trans Power Electron 30(4):1855-1865

24. Tang Y, Qin Z, Blaabjerg F, Loh PC (2015) A dual voltage control strategy for single-phase PWM converters with power decoupling function. IEEE Trans Power Electron 30(12):7060-7071

25. Tang Y, Loh PC, Wang P, Choo FH, Gao F, Blaabjerg F (2012) Generalized design of high performance shunt active power filter with output LCL filter. IEEE Trans Ind Electron 59(3):1443-1452

26. Holmes DG, Lipo TA (2003) Pulse width modulation for power converters: principles and practice. Wiley, Oxford

27. Wu W, He Y, Blaabjerg F (2012) An LLCL power filter for single-phase grid-tied inverter. IEEE Trans Power Electron 27(2):782-789

28. Xu J, Yang J, Ye J, Zhang Z, Shen A (2014) An LTCL filter for converters. IEEE Trans Power Syst 29(8):4322-4338

29. Chayjani MS, Monfared M (2016) Stability analysis and robust grid-connected filter for traps design of $\mathrm{LCL}$ with multitoned converters. IEEE Trans Ind Electron 63(11):6823-6834

30. Anzalchi A, Moghaddami M, Moghaddasi A, Sarwat A, Rathore AK (2016) A new topology of higher order power filter for singlephase grid-tied voltage source inverters. IEEE Trans Ind Electron 63(12):7511-7522

31. Fang J, Xiao G, Zhang Y (2015) An LCCL filter and its application to a half-bridge APF. In: International conference on power electronics and ECCE Asia (ICPE-ECCE Asia), Seoul

32. Wu W, Sun Y, Lin Z, Tang T, Blaabjerg F, Chung HS (2014) A new LCL-filter with in-series parallel resonant circuit for single-phase grid-tied inverter. IEEE Trans Ind Electron 61(9):4640-4644

33. Li F, Zhang X, Zhu H, Li H, Yu C (2015) An LCL-LC filter for the grid-connected converter: topology, parameter, and analysis. IEEE Trans Power Electron 30(9):5067-5077

34. Wu W, Sun Y, Lin Z, He Y, Huang M, Blaabjerg F (2014) A modified LLCL filter with the reduced conducted EMI noise. IEEE Trans Power Electron 29(7):3393-3402

35. Fang J, Li H, Tang Y (2017) A magnetic integrated LLCL filter for grid-connected voltage-source converters. IEEE Trans Power Electron 32(3):1725-1730

36. Fang J, Xiao G, Xu Y, Tang Y (2017) Parameter design of a novel series-parallel-resonant LCL filter for single-phase half-bridge active power filters. IEEE Trans Power Electron 32(1):200-217

37. Channegowda P, John V (2010) Filter optimization for grid interactive voltage source inverters. IEEE Trans Ind Electron 57(12):4106-4114

38. Azril M, Abd. Rahim N (2011) Design analysis of low-pass passive filter in single-phase grid-connected transformerless inverter. In: IEEE 1st conference on clean energy and technology CET, Kuala Lumpur, Malaysia

39. Büyük M, Tan A, Tümay M, Bayindir KC (2016) Topologies generalized designs passive and active damping methods of switching ripple filters For voltage source inverter: a comprehensive review. Renew Sustain Energy Rev 62:46-69

40. Wu W, Sun $Y$, Huang $M$, Wang $X$, Wang $H$, Blaabjerg F, Liserre $M$, Chung HS (2014) A robust passive damping method for LLCLfilter-based grid-tied inverters to minimize the effect of grid harmonic voltages. IEEE Trans Power Electron 29(7):3279-3289

Publisher's Note Springer Nature remains neutral with regard to jurisdictional claims in published maps and institutional affiliations. 